\title{
RESPONDING TO THE ECOLOGICAL CRISIS: TRANSFORMATIVE PATHWAYS FOR SOCIAL WORK EDUCATION
}

\author{
Peter Jones \\ James Cook University
}

\begin{abstract}
The nature and extent of the current ecological crisis raises the question: Does social work have a contribution to make in addressing the social and environmental changes required if we are to move toward a sustainable future? Given the links between the traditional concerns of social work and the emerging concerns of environmental and ecological justice, there is a strong argument to be made for expanding the ecological orientation of social work to include the nonhuman world. Transformative learning theory provides a model for how such a shift might be facilitated within social work education, emphasizing a focus on reflection, dialogue, and action.
\end{abstract}

OVER THE LAST DECADE, and more dramatically in the last few years, increasing evidence of major problems in the earth's ecological balance, particularly relating to the issue of global warming, has resulted in a dramatic increase in concern about ecological issues. In the face of the overwhelming evidence of climate change, it is difficult to argue that humans are having no impact, or only a benign impact, on the natural world. It is widely and generally agreed that humans have reached population levels and technological capacities that mean we are capable of destroying the fragile ecosystem that sustains us.

The fundamental conclusion drawn by much of the emerging evidence is that there is a crisis and we are the cause. Many recent reports also make the point that environmental problems inequitably affect the world's poorest and operate to further prevent many people from moving from poverty into more sustainable lifestyles (United Nations Environment Programme, 2007). The prominence of environmental issues in recent domestic political debate in the United Kingdom, the United States, and Australia makes it increasingly clear that the issue of the environment will continue to move from the periphery of economic and social policy to being one of the core issues, if not the core issue. Such a conclusion recognizes the centrality of the environment and the ways in which all aspects of 
human life are related back to the state of the global ecosystem. This acknowledgment also clearly links issues of global social justice with issues of the environment.

Given this level of recognition, it is an interesting and important exercise to think about social work's role in understanding and responding to the global ecological crisis, and to assess the ways in which the profession might build on existing theoretical and practice foundations to make a contribution to facilitating the social, economic, and political transformations that will be required to move the planet toward a sustainable future. On a philosophical level, this will require a paradigmatic shift in the way social work as a profession understands its role and purpose as well as its conceptualization of the relationship between people and the nonhuman world.

On a practical level, this philosophical shift will need to be facilitated by a pedagogical approach to social work education that is capable of challenging existing paradigms, critically evaluating emerging alternatives, and encouraging action grounded in new ways of understanding the world. Transformative approaches to social work education may help us to move toward the necessary goal of equipping students with an expanded ecological consciousness and a clear sense of the interdependence of social and environmental issues.

In this way, the ecological crisis presents both a challenge and an opportunity for social work. The challenge is to respond to an emerging dynamic, when that response may very well involve a fundamental reassessment of the values that underpin the profession.
The opportunity is to do exactly this, in a way that builds on social work's existing foundations, and in doing so place the profession in a position to make significant and meaningful contributions to the creation of an ecologically sustainable future.

\section{Social Work, Modernity, and the Environment}

Despite the increasing and urgent evidence of the ways in which the ecological crisis is impacting human well-being, and the obvious connections among the concerns of environmental, ecological, and social justice, social work has generally been reluctant to claim, or even explore, a role in the task of addressing this crisis and finding ways to move forward. A review of the major social work journals reveals a paucity of literature linking the profession and the natural environment, and although social work programs may include a consideration of environmentalism as an ideology or a social movement, there are few examples of courses devoted specifically to linking the social and ecological in theory and practice.

Yet a concern with people's environment has been described as one of the distinguishing features of the social work profession, and it was in the very earliest efforts at organized welfare that this became evident (Besthorn \& McMillen, 2002; Coates, 2003). This concern is often referred to as social work's "person-inenvironment" perspective. While social work was distracted from this emphasis in the mid 20th century by the emerging dominance of psychoanalytic models and the resulting focus on individualized approaches, a clear tradition of contextually oriented practice contin- 
ued throughout this time. This orientation was strengthened by the development of general systems theory (GST), a model for explaining the nature of organization in the natural world, and the influence that GST had in many broader fields, including social work (see, e.g., Hearn, 1969; Pincus \& Minahan, 1973). More recently, the emergence of "ecological" and "life" models within the social work profession has reemphasized the person-in-environment perspective (Germain, 1979; Germain \& Gitterman, 1980).

The existence and acceptance of these theoretical approaches within the profession is a significant factor when considering the need to develop an expanded ecological approach. The notion that the well-being of individuals, communities, and societies is clearly linked to the broader environment in which they are situated is already fundamental to most approaches to social work theory and practice (Narhi \& Matthies, 2001). The work of Germain (1979) and Germain and Gitterman (1980), for example, makes explicit the importance of context and draws our attention to the interactions between people and their environments in ways that clearly foreshadow the concerns of an expanded ecological approach. This need to expand and build upon existing foundations has been recognized by other authors seeking to incorporate new insights into existing models (see, e.g., Hudson, 2000), but the challenge here is to recognize that given the emerging concerns of the ecological crisis, these models may no longer be adequate, and, therefore, another dimension needs to be addressed.

In this sense, we need to recognize that when the terms environment and ecology are used in social work, they do not always, or even usually, refer to the same things that are meant when those terms are used in the natural sciences. Instead, many of the original ideas that were generated from observing and understanding the relationships and levels of interdependence in the natural world have been extracted and refined so that they can be applied to human beings in their social settings. During this process, the relationship between humans and the natural environment has, to a large extent, been ignored or excluded from the ongoing development of ecological or person-in-environment models in social work (Besthorn \& McMillen, 2002; Coates, 2003). Instead, a conceptualization of "environment" has been developed that is almost exclusively limited to a person's social environment, that is, a person's relationships with other individuals, groups, communities, and organizations.

In examining why social work has negated the importance of the natural world, a compelling analysis emerges of the relationship between the development of the profession and the characteristics of modernity (Coates, 2003; Hoff \& Polack, 1993). Coates (2003), for example, argues that as a product of modernity, social work has been shaped by, and to some extent acted as a facilitator of, the beliefs and values of modernity, which are themselves responsible for fostering a particular attitude toward the natural world. Flowing from the broad social movements of the Enlightenment, Scientific Revolution, and Renaissance, the emergence of modernity represented the shift from worldviews focused on fatalism and divine will toward an emphasis on rationality and scientific progress. A new set of beliefs 
came to characterize modern thought, including the ideas that humans are fundamentally different from all other creatures and have dominion over them, that people control their own destinies and can choose their paths independently, that the world presents unlimited opportunities for humans, and that progress is the solution and need never cease (Catton \& Dunlap, 1980).

A key dynamic in the development of modernity has been the privileging of dualistic beliefs that posit a clear distinction between humans and nature, and establish hierarchies with humans as the primary species. The primacy of the individual, an overreliance on empiricism and rationality, and a mechanistic view of the universe are all aspects of the beliefs of modernity. Callenbach (2005) links these values clearly with the rise of capitalism and expansionist industrialism, arguing that these are most clearly embodied in an uncritical acceptance of the need for continual growth. While it is clear that modernist values and beliefs have underpinned many positive developments, particularly in areas such as health care and communications, it is also now clear that, particularly in relation to the environment, there have been significant negative consequences as well.

In such an analysis, it can be argued that the same values and beliefs that underpin social exploitation and oppression, such as dualism, domination, and reductionism, also lead to ecological exploitation and destruction. For social work, characterized by Coates (2003) as a "domesticated" and codependent profession, the consequence of this relationship to the foundations of modernity is a con- ception of the ecological that is limited and, in many respects, inadequate.

This is not to say that approaches that attempt to account for the natural world and its relationship to human well-being have been completely absent from social work. On the contrary, as far back as 1993 Hoff and Polack, as well as Berger and Kelly, published articles examining the environmental crisis and its implications for social work (Berger \& Kelly, 1993; Hoff \& Polack, 1993). What was important about these articles, and others like them (see, e.g., Besthorn \& McMillen, 2002; Hillman, 2002; Hoff, 1994; Ife, 1997; Marlow \& Van Rooyen, 2001; Park, 1996), was the authors' argument that there were clear and undeniable associations between environmental issues and the traditional social issues with which social work is generally concerned. A number of authors have highlighted these connections by drawing attention both to broad issues, such as the links between poverty and environmental problems (Rogge \& Darkwa, 1996), and to more specific problems, including the exposure of children to chemical contamination (Rogge, 1996; Rogge \& Combes-Orme, 2003). Essentially, these authors argue that the adoption of a broader, ecologically oriented model for social work would create opportunities for the profession to make a valuable and necessary contribution to addressing the ecological crisis.

At the heart of this small but significant body of literature, and the perspective it represents, is the idea that eventually the problems facing the natural environment will begin to have such a clear impact on society that social workers will need to make the 
environment-physical as well as social—and our relationship to it central to our ongoing development of theory and practice. The current ecological crisis is revealing the false dualism that underpins the environmentsociety dichotomy and forcing us to come to grips with the importance of concepts such as ecological interdependence and interrelatedness. For social work as a profession, it also produces an argument for reflecting on the ways in which our origins and many of our underlying assumptions and values are grounded in the beliefs of modernity and for recognizing that a new type of thinking, underpinned by different values and beliefs, is required if we are to have a role in addressing the ecological crisis. For social work education, it challenges us to find models for equipping students with the values, knowledge, and skills that will be required in this endeavor.

\section{Directions for Education}

If we accept that social work may, and should, have a role to play in addressing the ecological crisis, then we are presented with the question: What is required for the profession and for social work education if this challenge is to be taken up? One answer is to simply "add on" the natural environment as one of the core issues with which the profession is concerned. To some extent, this is already happening, albeit slowly and with questionable impact, as mention of ecological sustainability creeps into social work mission statements (see, e.g., de Silva, 2006). However, there is a strong case to be made that such an approach will not produce the fundamental shift that is required if we are to grapple in a meaningful way with the ecological crisis.

The nature of this fundamental shift is one that moves us away from the anthropocentric approach that has been a core characteristic of much social work, toward a more ecocentric worldview. Ecocentric philosophies highlight the fact that humans do not stand above nature (Attfield, 2003; Eckersley, 1992). Such approaches point out that while technological development has greatly increased our ability to have an impact on global ecological processes, in every real sense we remain simply a single species in a complex ecological web, joined in myriad relationships with other species, and with nonliving components and systems within the ecological whole. We are part of nature, not separate from it. It is our perceived separation from nature, a form of environmental alienation, that lies at the heart of the ecological crisis. In this sense, it can be argued that we have lost sight of our place in the natural world and, perhaps most important, lost the sense of connection, of relationship to the other parts of the web. This matters because if we do not see or understand our relationship to something, then it is easy to ignore the impact that our actions might have, and to not recognize or care about the consequences of that impact.

For decades now environmental philosophers and ethicists have grappled with the nature and consequences of anthropocentrism and the merits and varieties of ecocentric alternatives (see, e.g., Bookchin, 1995; Paavola \& Lowe, 2005; Stenmark, 2002). It would be a mistake, however, to think that the importance of environmental philosophy is restricted to 
abstract conceptualizations of our relationship to, and place within, the environment. In fact, the fundamental, ontological assumptions that underpin these belief systems have direct and practical implications in many areas of our lives. The public policies developed by governments are shaped by particular ways of thinking about these issues, and these extend through areas that have direct relevance for social work, including the nature and orientation of economic, political, legal, health, and education systems. Indeed, some commentators have argued that if the ecological crisis continues to deepen, such philosophical debate will be of direct relevance when considering the very nature of participatory democracy and authoritarianism (Dobson, 2007; Low \& Gleeson, 2001). Consideration of this dimension alone-the links among ecology, public policy, and democracy-should alert the profession to the need for an expansion of existing ecological approaches, and a deeper concern and engagement with issues of the natural environment.

Although within some areas of higher education there is a growing perception of the need for such an expanded ecological knowledge and awareness (see, e.g., Moody \& Hartel, 2007; Shephard, 2008), there is as yet little evidence of such a shift within social work. Yet outside of the profession there are some strong arguments as to what is actually required, particularly in relation to the role that higher education must play. Capra (2002), for example, has described the process of increasing academic specialization and noted the way in which this has served to alienate the social sciences from "the world of matter" (p. xix). He argues that such a division will no longer be possible because, in the near future, all disciplines will need to become focused on the quest for ecological sustainability.

Similarly, Orr $(1992,1999)$ advocates for the importance of having educational systems that develop students' ecological literacy-the idea that we must reclaim and reconnect to our understanding of the natural world. $\mathrm{He}$ argues that the Western educational model needs to be changed if we are to address the ecological crisis. O'Sullivan $(1999,2002)$ has also approached the question of learning for ecological sustainability by engaging in a farreaching and visionary articulation of a new form of education, one he refers to as a “transformative-ecozoic education" (1999, p. 6). It is an educational vision that is profoundly holistic and integral. He argues that the features of such an educational approach will include an orientation to knowledge that is synthetic and holistic; that is time developmental in nature; and that includes "earth education," which, according to O'Sullivan, means "not education about the earth, but the earth as the immediate self-educating community of those living and non-living beings that constitute the earth" (1999, p. 76).

Building on similar arguments, but with a specifically social work focus, Besthorn (2008) calls for an ecological revolution in social work education. He argues that if the profession is to meet the challenge of the current crisis, then social work needs to move toward a deepecological consciousness. Besthorn describes such a consciousness as converging along three dimensions: environmental awareness, spiritual sensitivity, and political activism. Each of these dimensions is clearly interrelated with the others. However, it is perhaps the first 
of these, the development of environmental awareness, or ecological literacy, where social work education has the greatest potential to build upon existing approaches, both theoretical and practical, and make a significant shift toward a more fully ecological orientation.

\section{A Way Forward: Transformative Learning in Social Work}

As social work educators, if we accept the need for a new paradigm in social work theory and practice, one that is capable of encompassing ecological considerations, then we must turn our attention to the impact of this idea on the theory and practice of social work education. Based on the arguments I have presented, what is required is an educational approach that not only facilitates critical reflection on the assumptions that underpin the dominant paradigm of modernity but also allows such critical reflection to be directed at the ways in which these assumptions have shaped individual beliefs, values, and behaviors. The pedagogical approach should also allow for the introduction and consideration of alternative perspectives and for these to be tested out in the social world through both discourse and action. Transformative learning theory, as developed by Jack Mezirow (1990, 1991, 2000, 2003) and others (see, e.g., Brookfield, 2000; Cranton, 2002; Dirkx, 2006; Taylor, 2006), provides such an organizing framework for social work education, both as an explanatory theory of learning and as a guide for educational practice.

The concept of transformative learning has proven to be one of the most generative lines of scholarship in the field of adult learning, creating opportunities for wide-ranging discussion and debate about the nature of adult learning and of its relationship to personal and social change (Dirkx, 2006; Marsick \& Mezirow, 2002). At its heart, transformative learning theory is about the nature of change, about the processes through which we produce a shift in the way we see and make meaning of the world. Mezirow, one of the leading proponents of this theoretical orientation, describes transformative learning as "learning that transforms problematic frames of reference-sets of fixed assumptions and expectations (habits of mind, meaning perspectives, mindsets)—to make them more inclusive, discriminating, open, reflective, and emotionally able to change" (2003, pp. 58-59).

Central to this theory is the concept of structures of meaning-the frames of reference that we acquire uncritically through processes of socialization and acculturation and that are often distorted as a result of the internalization of the dominant sociocultural assumptions prevailing in our social context. Transformative learning is said to occur in those situations where we become aware of the inadequacy of these frames of reference (often through an explicit, disorienting experience) and subsequently engage in critical reflection on their very basis. This critical reflection may, in turn, lead to the awareness of alternative ways of thinking and to testing out such alternatives through dialogue and action (Mezirow, 1990, 1991, 2000, 2003).

The importance placed on reflecting on fundamental assumptions as part of the process of developing and enacting a new worldview makes transformative learning theory particularly important when considering the direction social work education may need 
to move in if we are to develop a new, ecologically oriented approach to theory and practice. Mezirow (2000) has suggested that there are two key types of reflection involved in the transformative process: first, critical reflection of assumptions, or objective reframing, which involves critically reflecting on the assumptions of others; and, second, critical selfreflection of assumptions, or subjective reframing, which involves critical reflection on one's own assumptions and in particular the ways in which one's worldview may be limited and distorted (Taylor, 1998).

Both of these forms will be critical to the development of an ecologically oriented social work. Encouraging students to critically consider the assumptions, values, and beliefs of modernity, and the ways in which these are implicated in the current ecological crisis, will be an essential step in developing a new worldview. Equally important, however, will be creating the space within which students can reflect on the ways in which the presuppositions of the dominant paradigm have shaped their personal worldviews and their own values and beliefs, particularly the way in which they see their relationship with the nonhuman world.

The second of the key processes of transformative learning relates to the role and importance of rational discourse, or, as Mezirow (2003) more recently refers to it, critical-dialectical discourse. Mezirow's argument here, building on the work of Habermas (1984), is that critical reflection on underlying assumptions, such as would lead to perspective transformation, is not a solitary activity; rather, it takes place, at least in part, through discourse. Discourse here refers to "the process in which we have an active dialogue with others to better understand the meaning of an experience" (Mezirow, 2000, p. 14). In particular, Mezirow is concerned with dialogue devoted to assessing contested beliefs, and it is through such discourse that the process of transformation is promoted, developed, and enacted. As Taylor (1998) notes, "It is within the arena of rational discourse that experience and critical reflection are played out. Discourse becomes the medium for critical reflection to be put into action" (p. 11).

In pursuit of an expanded ecological consciousness, a central task for social work education will be to break through the existing level of ecological alienation and encourage students to reevaluate their relationship to the nonhuman world. Developing such an awareness of their connections to the natural world and of the nature and extent of the ecological crisis will, for many students, constitute a disorienting dilemma-a recognition that our old ways of thinking and acting are no longer sufficient and that we need to seek out new models and ways of being. Critical reflection on the sociocultural assumptions that have led to the crisis, and the ways in which we have internalized these, will lead to a search for alternatives. The paths suggested by writers such as O'Sullivan (2002) and Orr (1999), who call for the development of an expanded environmental awareness and ecological literacy, then need to be considered and assessed, and it is through critical-dialectical discourse that such assessment may occur. A task for social work education is therefore to create both awareness of these alternatives and the dialogical spaces in which students can openly 
engage in a critical assessment of their merits and validity.

Most transformative learning theorists agree that such learning can be said to have truly occurred only when it produces action based on the newly transformed frames of reference. The emphasis on praxis is an important dimension of this theory when viewed in relation to the task of developing an ecologically oriented social work. Faced with the enormity of the ecological crisis, social work education must look to pedagogy with an explicit orientation toward change, at both the individual and social levels. For Mezirow, transformative learning is not necessarily linked directly and inevitably to social change. Perspective transformation may, for instance, relate to epistemic or psychic distortions, and while transforming these existing presuppositions will entail taking action in the social world, such action may relate more to individual behavior than direct, collective, social action (Mezirow, 1991). However, and importantly, Mezirow (2003) argues that processes of transformative learning help to create the conditions for both individuals and society that are necessary for emancipatory social transformation and engagement in participative, democratic processes.

In many respects a great deal of social work education already incorporates some aspects of a transformative approach. Critical reflection, for example, has emerged as a core component and concern of social work education and practice (see, e.g., Clare, 2007; Fook \& Askeland, 2007; Gould \& Taylor, 1996; Napier \& Fook, 2000; Osmond \& Darlington, 2005; Redmond, 2005; Sheppard, 1998; Yelloly \& Henkel, 1995; Yip 2006). Similarly, dialogical approaches have been recognized as invaluable to social work education (see, e.g., Ross, 2007; Rozas, 2004; Tsang, 2007), and there is a continuing recognition of the importance of experiential learning and praxis (Anderson \& Harris, 2005; Carey, 2007; Gibbons \& Gray, 2002). However, as noted by Coates (2003), Besthorn (2008), and others, these approaches are often put to use in the service of a social work whose view of environment and ecology is narrowly conceived and therefore has failed to grapple meaningfully with the transformations required if we are to address the ecological crisis.

\section{Facilitating Ecological Transformation}

The challenge for social work educators is to integrate transformative learning theory with a range of existing methods focused on reflective, dialogic, and experiential approaches, and to apply this theory and method to the development of ecological awareness and literacy among students. In my own teaching practice, this process is often begun with an attempt at producing a disorienting dilemma-an experience that alerts students to the limitations of their existing frames of reference in relation to the environment. Challenging students on the nature and extent of their environmental alienation is often a good place to start. Responses to questions such as "How many native plant species endemic to our region can you name?", "Who can describe both the location and process of sewage disposal in our community?", and "Where are the boundaries of our local catchment area [or bioregion]?" often reveal the poor levels of environmental literacy 
among students. It is then that the question, "Why don't we know the answers to these questions?" should be raised.

Getting students out of the classroom setting also helps to rattle their existing frame of reference. In the course I teach on eco-social justice, we often hold classes off campus, visiting degraded waterways, revegetation projects, community gardens, and suburban subdivisions. In all of these settings it is instructive to see students realize how much they do not know about both the natural world and our impact on it. The depth of this realization is often apparent in students' reflections on the experience.

A wide range of activities can be employed to help challenge students' preconceptions and reveal blind spots in their own knowledge and understanding (for an example, see Appendix A). For many, such disorienting experiences are enough to open the door to an active and enthusiastic engagement in critical reflection on the assumptions inherent in our society and the connection between these assumptions and our own values, beliefs, and experiences.

Developing forms of assessment that promote both objective and subjective reframing is also an essential component of a transformative approach to expanding ecological awareness. In various iterations of the ecosocial justice course mentioned earlier, assessment has included autophotography, reflective learning portfolios, and critically reflective autobiographies. All of these forms have the advantage of being able to incorporate critical engagement with conceptual material, such as a consideration of the foundations of modernity, with students' own lived experience. The most recent form in use in this course, for example, asks students to write an autobiographical piece (as overview, or focusing on critical incidents) that illustrates the degree to which the values of modernity have, or have not, impacted their personal relationship with the nonhuman world (see Appendix B). Based on the experiences of students involved with these tasks, such critically reflective processes can be very challenging but are also often rewarding.

Challenging students' existing beliefs and facilitating reflection on the sources and impact of those beliefs are important steps in creating the potential for learning and change. There is a danger, however, that if the process stops there students may be "stranded"aware that their existing frames of reference are limited, but unclear as to how they might move forward. Creating safe and supportive spaces for dialogue and rational discourse then becomes an essential part of the transformative process. In particular, students need opportunities to explore and assess the validity of alternative ways of seeing and being in the world. Debates around our place on the anthropocentric-ecocentric continuum are often useful in this regard, as are visioning exercises that encourage students to imagine the possibilities and day-to-day realities of an ecologically sustainable society.

The transition from abstract concepts to practical action is also a crucial phase of the transformative learning process for the profession of social work and social work education. Students need to be given opportunities to take action to test out their newly expanded frames of reference. Various models of service learning could be applied here, including participation in environmental projects as 
part of course design, but where practical constraints make this difficult other approaches may be useful. In my experience, students are often simply unaware of the range of possible actions they could take-as individuals and collectively, personally and professionallythat would contribute to the social transformations required if we are to address the ecological crisis.

Presenting a range of ecoactions, or socioenvironmental strategies, at various levels of social organization, and providing examples of practice and activism grounded in an ecological paradigm, give students a starting point for considering what actions they themselves can take. This is also an important opportunity for educators to model their own eco-oriented practice, providing students with powerful examples of the ways in which an ecological orientation may actually manifest in the practice of a social worker. Considering the possibilities for action often leads students to test such action in their own lives and, importantly, in their own practice.

Although such actions may initially be small scale and often individual in nature, this is an important step in testing transformed frames of reference and in enacting change in the social world. Truly transformative learning will also be characterized by persistence, so it is encouraging to hear from past students about the ways in which an ecological orientation has manifested itself in professional practice. For example, describing her work in a migrant support program with an environmental focus, a social work graduate recently wrote: "I am writing to tell you all this because I never expected in my wildest dreams that I would get involved this much into envi- ronmental issues. I actually thought of the subject as a waste of time in the beginning. Now I am learning more and realise how crucial it is for community sustainability."

It is hoped that what these small steps represent is the beginning of the process whereby social work, building on its existing foundation of a concern for people in their environment, shifts from a thoroughly anthropocentric, modernist orientation toward an expanded ecological perspective. If social work is to have a role in addressing the ecological crisis, this shift will be essential. Transformative learning provides an example of an educative model that can be used in building the foundations of this shift in social work education, but only if the will to do so is present. In this sense then, while a transformative learning approach will be invaluable in developing the theoretical and practical orientation required for an ecologically oriented social work education, the fundamental task is that of first recognizing the urgency and validity that underpins this need.

\section{Conclusion}

The ecological crisis represents both a challenge and an opportunity for social work and social work education. As a profession that has always been deeply concerned with the interactions between people and their environments, social work is well placed to build on existing theory and practice to develop an expanded ecological approach. Such an approach will allow the profession to better position itself to respond to the many challenges that lie ahead as the ecological crisis manifests itself more clearly and urgently, particularly in forms that relate directly to 
issues of social justice. Given the many examples of the profession adapting to meet emerging social issues in the past, there is good reason to feel optimistic about the potential for social work to rise to this latest challenge. Social work education must play a key role in this process if that optimism is to be justified.

Transformative learning theory suggests a way forward for social work education in the face of the growing awareness of this need for change. In its emphasis on critical reflection and critical self-reflection, it suggests an approach that links the personal with the political-pursuing the goals of critical theory through ideology critique, but joining these to our individual experience. It also emphasizes the centrality of dialogue and rational discourse through a commitment to engaging openly with others in assessing the validity of alternative pathways, including, in this case, ideas around ecological literacy and an expanded ecological consciousness. More important, for social work in particular, it also manifests an action orientation, seeing learning as truly occurring when it translates into change both at the level of individual behavior and through political action for social transformation. Such change will be essential if we are to address the ecological crisis successfully.

\section{References}

Anderson, D., \& Harris, B. (2005). Teaching social welfare policy: A comparison of two pedagogical approaches. Journal of Social Work Education, 41, 511-526.

Attfield, R. (2003). Environmental ethics: An overview for the twenty-first century. Cambridge: Polity Press.
Berger, R., \& Kelly, J. (1993). Social work in the ecological crisis. Social Work, 38, 521-526.

Besthorn, F. H. (2008, April). Toward a deepecological social work: Its environmental, spiritual and political dimensions. Global Alliance for a Deep Ecological Social Work. Retrieved June 20, 2008, from http:// www.ecosocialwork.org/prspctvs.html

Besthorn, F., \& McMillen, D. (2002). The oppression of women and nature: Ecofeminism as a framework for an expanded ecological social work. Families in Society, 83, 221-232.

Bookchin, M. (1995). The philosophy of social ecology: Essays on dialetical naturalism. Montreal: Black Rose Books.

Brookfield, S. (2000). Transformative learning as ideology critique. In J. Mezirow \& Associates (Eds.), Learning as transformation: Critical perspectives on a theory in progress (pp. 125-148). San Francisco: Jossey-Bass.

Callenbach, E. (2005). Values. In M. Stone \& Z. Barlow (Eds.), Ecological literacy: Educating our children for a sustainable world (pp. 45-48). San Francisco: Sierra Club Books.

Capra, F. (2002). The hidden connections: Integrating the biological, cognitive, and social dimensions of life into a science of sustainability. New York: Random House.

Carey, L. (2007). Teaching macro practice: An experiential learning project. Journal of Teaching in Social Work, 27(1/2), 61-71.

Catton, W., \& Dunlap, R. (1980). Overshoot: The ecological basis of revolutionary change. Urbana: University of Illinois Press.

Clare, B. (2007). Promoting deep learning: A teaching, learning and assessment endeavour. Social Work Education, 26, 433-446. 
Coates, J. (2003). Ecology and social work: Toward a new paradigm. Halifax: Fernwood Publishing.

Cranton, P. (2002). Teaching for transformation. New Directions for Adult and Continuing Education, 104, 63-71.

de Silva, E. C. (2006). Human rights and human needs. NASW News, 51(6). Retrieved June 20, 2008, from http:/ / www. socialworkers.org/pubs/news / 2006/06/ desilva.asp

Dirkx, J. (2006). Engaging emotions in adult learning: A Jungian perspective on emotion and transformative learning. New Directions for Adult and Continuing Education, 109, 15-26.

Dobson, A. (2007). Green political thought (4th ed.). London: Routledge.

Eckersley, R. (1992). Environmentalism and political theory: Toward an ecocentric approach. London: UCL Press.

Fook, J., \& Askeland, G. (2007). Challenges of critical reflection: "Nothing ventured, nothing gained." Social Work Education, 26, 520-533.

Germain, C. (Ed.). (1979). Social work practice: People and environments - an ecological perspective. New York: Columbia University Press.

Germain, C., \& Gitterman, A. (1980). The life model of social work practice. New York: Columbia University Press.

Gibbons, J., \& Gray, M. (2002). An integrated and experience-based approach to social work education: The Newcastle model. Social Work Education, 21, 529-549.

Gould, N., \& Taylor, I. (Eds.). (1996). Reflective learning for social work. Aldershot, UK: Arena.
Habermas, J. (1984). The theory of communicative action: Reason and the rationalization of society (T. McCarthy, Trans.). Boston: Beacon Press.

Hearn, G. (Ed.). (1969). The general systems approach: Contributions toward an holistic conception of social work. New York: Council on Social Work Education.

Hillman, M. (2002). Environmental justice: A crucial link between environmentalism and community development? Community Development Journal, 37(4), 349-360.

Hoff, M. (1994). Environmental foundations of social welfare: Theoretical resources. In M. Hoff \& J. McNutt (Eds.), The global environmental crisis: Implications for social welfare and social work (pp. 12-35). Aldershot, UK: Avebury.

Hoff, M., \& Polack, R. (1993). Social dimensions of the environmental crisis: Challenges for social work. Social Work, 38, 204-211.

Hudson, C. (2000). At the edge of chaos: A new paradigm for social work? Journal of Social Work Education, 36, 215-230.

Ife, J. (1997). Community development: Creating community alternatives-vision, analysis and practice. South Melbourne, Australia: Longman.

Low, N., \& Gleeson, B. (2001). The challenge of ethical environmental governance. In $\mathrm{N}$. Low \& B. Gleeson (Eds.), Governing for the environment: Global problems, ethics and democracy (pp. 1-25). Basingstoke, UK: Palgrave.

Marlow, C., \& Van Rooyen, C. (2001). How green is the environment in social work? International Social Work, 44, 241-254.

Marsick, V., \& Mezirow, J. (2002). New work on transformative learning. Teachers College 
Record. Retrieved June 10, 2007, from http: / / www.tcrecord.org

Mezirow, J. (1990). How critical reflection triggers transformative learning. In J. Mezirow \& Associates (Eds.), Fostering critical reflection in adulthood: A guide to transformative and emancipatory learning (pp. 1-20). San Francisco: Jossey-Bass.

Mezirow, J. (1991). Transformative dimensions of adult learning. San Francisco: Jossey-Bass.

Mezirow, J. (2000). Learning to think like an adult: Core concepts of transformation theory. In J. Mezirow \& Associates (Eds.), Learning as transformation: Critical perspectives on a theory in progress (pp. 3-33). San Francisco: Jossey-Bass.

Mezirow, J. (2003). Transformative learning as discourse. Journal of Transformative Education, 1(1), 58-63.

Moody, G., \& Hartel, P. (2007). Evaluating an environmental literacy requirement chosen as a method to produce environmentally literate university students. International Journal of Sustainability in Higher Education, 8, 355-370.

Napier, L., \& Fook, J. (2000). Breakthroughs in practice: Theorising critical moments in social work. London: Whiting \& Birch.

Narhi, K., \& Matthies, A. (2001). What is the ecological (self-)consciousness of social work? In A. Matthies, K. Narhi \& D. Ward (Eds.), The eco-social approach in social work (pp. 16-53). Jyvaskyla, Finland: SoPhi.

Orr, D. (1992). Ecological literacy: Education and the transition to a postmodern world. Albany: State University of New York Press.

Orr, D. (1999). Rethinking education. The Ecologist, 29, 232-234.
Osmond, J., \& Darlington, Y. (2005). Reflective analysis: Techniques for facilitating reflection. Australian Social Work, 58, 3-14.

O'Sullivan, E. (1999). Transformative learning: Educational vision for the 21st century. London: Zed Books.

O'Sullivan, E. (2002). The project and vision of transformative education: Integral transformative learning. In E. O'Sullivan, A. Morrell, \& M. A. O'Connor (Eds.), Expanding the boundaries of transformative learning (pp. 1-12). New York: Palgrave.

Paavola, J., \& Lowe, I. (2005). Environmental values in a globalising world: Nature, justice, and governance. London: Routledge.

Park, K. (1996). The personal is ecological: Environmentalism of social work. Social Work, 41, 320-323.

Pincus, A., \& Minahan, A. (1973). Social work practice: Model and method. Itasca, IL: Peacock.

Redmond, B. (2005). Reflection in action: Developing reflective practice in health and social services. Aldershot, UK: Ashgate.

Rogge, M. E. (1996). Social vulnerability to toxic risk. Journal of Social Service Research, 22(1/2), 109-129.

Rogge, M. E., \& Combes-Orme, T. (2003). Protecting children from chemical exposure: Social work and U.S. social welfare policy. Social Work, 48, 439-450.

Rogge, M. E., \& Darkwa, O. K. (1996). Poverty and the environment: An international perspective. International Social Work, 39, 395-409.

Ross, D. (2007). A dis/integrative model for social work education. Social Work Education, 26, 481-495. 
Rozas, L. (2004). On translating ourselves: Understanding dialogue and its role in social work education. Smith College Studies in Social Work, 74(2), 229-242.

Shephard, K. (2008). Higher education for sustainability: Seeking affective learning outcomes. International Journal of Sustainability in Higher Education, 9(1), 87-98.

Sheppard, M. (1998). Practice validity, reflexivity and knowledge for social work. British Journal of Social Work, 28, 763-781.

Stenmark, M. (2002). Environmental ethics and policy making. Aldershot, UK: Ashgate.

Taylor, E. W. (1998). The theory and practice of transformative learning: A critical review. Columbus, OH: ERIC Clearinghouse on Adult, Career, and Vocational Education. (ERIC Document Reproduction Service No. 423422)
Taylor, E. W. (2006). The challenge of teaching for change: Fostering transformative learning in the classroom. New Directions for Adult and Continuing Education, 108, 91-95.

Tsang, N. (2007). Reflection as dialogue. British Journal of Social Work, 37, 681-694.

United Nations Environment Programme. (2007). Global environment outlook: Environment for development (GEO4). Retrieved May 7, 2008, from http://www.unep. org/geo/geo 4

Yelloly, M., \& Henkel, M. (Eds.). (1995). Learning and teaching in social work: Towards reflective practice. London: Jessica Kingsley.

Yip, K. (2006). Reflectivity in social work practice with mental-health illness: Promise and challenge in social work education. International Social Work, 49, 245-255.

Accepted: 07/09

Peter Jones is senior lecturer at James Cook University.

Address correspondence to Peter Jones, James Cook University, Department of Social Work and Community Welfare, Douglas, Townsville, Queensland 4811, Australia; e-mail: peter.jones1@jcu.edu.au. 


\section{Appendix A. Examples of Exercises Used in Producing Disorienting Dilemmas}

\section{Exercise 1: Community Walk}

Students are taken in groups to walk around a neighborhood in a typical suburban subdivision. A recording sheet is provided that asks students to observe the neighborhood as an example of planning, with particular emphasis on features that relate to social and ecological sustainability. The facilitator encourages students to voice their observations as the walk proceeds. Often, the students are more "tuned in" to social rather than environmental characteristics. The role of the facilitator is to raise questions that link the social with the environmental and that may act to reveal students' lack of knowledge or awareness of environmental issues. Examples of such questions may include the following:

- Where does the electricity consumed in this community come from?

- Where does the waste from this community go?

- Why are the houses in this community designed the way they are? How does their design relate to the locale/climate?

In each of these instances, students may struggle to provide the answers. After some discussion of this situation the facilitator asks the key second-tier question: Why don't we know this information? Responses to this question can be used to illustrate the concept of environmental alienation and the ways that our methods of social organization serve to separate us from key ecological processes such as the consumption of resources and production of waste.

\section{Exercise 2: Environmental Site Visit}

Taking students out of the classroom often opens them up to new ways of looking at issues. In this exercise, students are taken in groups to an environmental site that may be an example of either a pristine or degraded ecosystem. One of the most successful sites in the author's experience is a riparian environment that has been the site of a community rehabilitation and revegetation project. Students should be allowed to wander and observe the area for some time before the facilitator calls them together and asks them to begin thinking about and articulating the links between this natural environment and the range of social issues with which social work might normally be concerned.

It is often the case that students struggle to identify links, missing obvious connections between issues such as clean water and human health and well-being. The facilitator can use this opportunity to produce further "discomfort" by asking students to articulate their knowledge of basic ecological processes, such as carbon and water cycles. While some students may recall aspects of these from high school science classes, many will have forgotten or possess only partial knowledge of these processes and, more important, their significance to human well-being.

As with Exercise 1, the key here is to ask students why we do not have this knowledge and understanding, and to encourage discussion of the currently dominant values and beliefs in society and how these lead to the privileging of some kinds of knowledge and information over others. 
In both of these exercises the facilitator is drawing attention to areas of knowledge that students do not possess. The aim is not to leave students feeling that they are inadequate but, rather, to get them to reflect on this deficit and the explanations for it, with particular reference to the dominant values and beliefs of society. The facilitator may ask for volunteers to research answers to some of the difficult questions that have been asked and for these to be shared at the next class.

\section{Appendix B. Example of Eco-Social Assessment}

\section{Critical, Ecological Autobiography}

This subject (WS3214: Developmental approaches to eco-social justice) presents an argument that the dominant paradigm of thought in Western society, based on the principles and values of modernity, has resulted in the development of a particular type of relationship between humans and the nonhuman world. The consequences of this relationship are evident in the ecological crisis that now confronts the globe. The modernist paradigm has also shaped the nature of social welfare theory and practice. A new paradigm, based on an expanded ecological awareness, is proposed as a pathway forward, both in a broad ontological sense and, more particularly, within the social welfare professions. The subject exposes students to a range of conceptual and theoretical material that supports this analysis.

However, if we as individuals, and as future social welfare practitioners, hope to make a contribution to the social transformation suggested by this material, then we must also become critically conscious of the ways in which the dominant paradigm has shaped our own understanding of, and relationship to, the nonhuman world. In other words, we must use the tools of critical reflection to expose and understand the nature of our own lived experience and the connection between this unique biographical story and the broader issues of eco-social justice.

This assignment aims to allow students to construct bridges of understanding between abstract conceptual material (such as the concepts of modernity, cosmogenesis, and ecological justice) and their own experience by writing about their own experience in a critically reflective manner, informed and framed by your engagement with these concepts and ideas. In this sense, this assignment represents an autobiographically informed account of students' understanding of the conceptual material presented in the first half of the subject.

Critical reflection can be conceived of and defined in a range of ways; however, for the purpose of this assignment, critical reflection can be thought of as involving thinking back over, then critically commenting on, what has happened in students' life/experience, using the conceptual material presented in the subject to shape and inform their commentary. The idea is that such reflection may lead to new learning and insights, which can then be used to improve future action and practice. 


\section{Task for Students}

Write a critically reflective account of your own life/ experience. The account must

- focus on the nature of your relationship with the nonhuman world;

- link your personal experience to a demonstration of your understanding of the principles and values of modernity, the concept of anthropocentrism, and the nature of the current ecological crisis;

- discuss the implications of your biographi- cal experience and conceptual understanding for your own social welfare practice.

As well as submitting the written piece of work, you need to give a brief (10- to 12minute-maximum) presentation to your tutorial group reflecting on your experience of completing the assignment and highlighting the most significant connections between your lived experience and the subject conceptual material. The timetable for these presentations will be determined early in the semester. 